\title{
Increased oxygen pulse after lung volume reduction surgery is associated with reduced dynamic hyperinflation
}

\author{
Matthew R. Lammi*, David Ciccolella*, Nathaniel Marchetti*, \\ Malcolm Kohler ${ }^{\#}$ and Gerard J. Criner*
}

ABSTRACT: Stroke volume augmentation during exercise is limited in chronic obstructive pulmonary disease patients because of decreased preload from dynamic hyperinflation (DH). We hypothesised that oxygen pulse and pulse pressure (PP) improve following lung volume reduction surgery (LVRS), and the magnitude of improvement correlates with reduction in $\mathrm{DH}$.

We compared 16 emphysema patients undergoing LVRS with six emphysema patients not undergoing LVRS. Oxygen pulse and PP were calculated from maximal cardiopulmonary exercise tests at baseline and 6 months. End-expiratory lung volume (EELV)/total lung capacity (TLC) represented $\mathrm{DH}$. Comparisons were made between baseline and 6 months at metabolic isotimes (per cent maximal carbon dioxide production $\left(V^{\prime} \mathrm{CO}_{2}, \mathrm{max}\right)$ ).

At baseline, the LVRS group was older with higher forced expiratory volume in $1 \mathrm{~s}$, but had similar hyperinflation to the non-LVRS group. At 6 months, oxygen pulse $(50 \%, 75 \%$, and $100 \%$ $\left.V^{\prime} \mathrm{CO}_{2}, \max \right)$ and PP (50\% and $75 \% V^{\prime} \mathrm{CO}_{2}$, max) increased in the LVRS, but not in the non-LVRS group. Baseline functional residual capacity/TLC inversely correlated with resting oxygen pulse $(r=-0.449, p=0.04)$. Decreased EELV/TLC correlated with increased oxygen pulse at $75 \%$ $(r=-0.487, p=0.02)$ and $100 \% V^{\prime} \mathrm{CO}_{2}, \max (r=-0.548, p=0.008)$.

LVRS led to increased oxygen pulse and PP during exercise at metabolic isotimes 6 months following surgery. Reductions in $\mathrm{DH}$ correlated with increases in oxygen pulse during exercise. Reducing lung volume may improve stroke volume response to exercise by decreasing $\mathrm{DH}$.

KEYWORDS: Cardiopulmonary interactions, chronic obstructive pulmonary disease, exercise, physiology

hronic obstructive pulmonary disease (COPD) patients have impaired exercise tolerance, which limits their quality of life. While ventilatory limitations, including dynamic hyperinflation $(\mathrm{DH})$, are the main cause of exercise intolerance in this population [1], causes for this impairment are probably multifactorial [2].

Impairment in cardiac mechanics in COPD may be one of the most important contributing factors. Stroke volume is reduced in COPD, especially during exercise [3]. Decreased stroke volume is due to increased intrathoracic pressures and decreased cardiac right-sided filling [4-6].

Along with its beneficial effects on mortality [7] and pulmonary function [8], lung volume reduction surgery (LVRS) improves exercise capacity by altering lung mechanics [7, 9, 10]. LVRS also favourably affects stroke volume, both at rest [8] and during exercise [11]. Increased right ventricular stroke volume post-LVRS has been reported to correlate with decreased resting hyperinflation [11]. The effect of $\mathrm{DH}$ on cardiac function during exercise in COPD, however, is unknown.

To investigate the effect of DH and LVRS on cardiac performance during exercise, we retrospectively analysed data from emphysema patients who had cardiopulmonary exercise tests (CPETs) before and after LVRS, and compared their changes with those who did not undergo LVRS. We hypothesised that LVRS would lead to an increase in non-invasive markers of stroke volume (oxygen pulse [12-14] and pulse pressure (PP) $[15,16])$ during exercise and that these improvements would correlate with a reduction in $\mathrm{DH}$.
AFFILIATIONS

${ }^{*}$ Temple University School of Medicine, Philadelphia PA, USA. \#University Hospital Zurich, Zurich, Switzerland.

CORRESPONDENCE

M.R. Lammi

Section of Pulmonary and Critical

Care Medicine

Temple University Hospital

3401 N. Broad St

7th floor Parkinson Pavilion

Philadelphia

PA 19140

USA

E-mail: lammi79@gmail.com

Received:

Sept 302011

Accepted after revision:

Dec 162011

First published online:

Jan 202012 


\section{METHODS AND MATERIALS}

\section{Study design and patient selection}

This was a retrospective, observational analysis. 16 patients were consecutively evaluated from our LVRS programme (February 2004-November 2005). All patients included in this study underwent bilateral LVRS following Center for Medicare/Medicaid Services approval of the procedure in January 2004 and met standard criteria for LVRS [7]. Patients with a left ventricular ejection fraction $<45 \%$, pulmonary hypertension or significant coronary artery disease were excluded from LVRS. Six emphysema patients who did not undergo LVRS (non-LVRS group) due to diffuse disease were consecutively selected from our advanced lung disease clinic. These patients were part of the medical arm of a clinical trial. All patients underwent CPETs after pulmonary rehabilitation (baseline) and 6 months later (after surgery in the LVRS group). All patients were maximally treated with bronchodilators and oxygen if indicated, and none were current smokers. Temple University Hospital (Philadelphia, PA, USA) institutional review board approval was obtained to analyse patient data (protocol number 13477).

\section{Data collection}

Pulmonary function testing

Pulmonary function testing was performed at baseline and again at 6 months. Spirometry was performed according to American Thoracic Society/European Respiratory Society (ATS/ERS) guidelines [17] before and after the administration of a bronchodilator. The reference standard used was the National Health and Nutrition Examination Survey III [18]. Post-bronchodilator values for forced expiratory volume in $1 \mathrm{~s}$ (FEV1), total lung capacity (TLC) and residual volume (RV) were used in the subsequent analyses. Lung volumes were measured by body plethysmography [19] and diffusing capacity of the lung for carbon monoxide [20] measurements were performed using standard techniques.

\section{Cardiopulmonary exercise testing}

CPET was performed on a braked cycle ergometer (ViaSprint 150P; ViaSys Healthcare, Hoechberg, Germany) according to ATS/ERS guidelines [21] using the protocol employed in the National Emphysema Treatment Trial (NETT) [9]. Exercise was performed while breathing oxygen through a mouthpiece with a calibrated pneumotachograph. Patients exercised on supplemental oxygen so that hypoxaemia was not a factor in limiting exercise performance, at the same inspiratory oxygen fraction $\left(\mathrm{FI}, \mathrm{O}_{2}\right)(30 \%)$ at baseline and 6 months later. A metabolic cart (VMax Encore; ViaSys Healthcare) was used to measure oxygen uptake $\left(V^{\prime} \mathrm{O}_{2}\right)$ and carbon dioxide production $\left(V^{\prime} \mathrm{CO}_{2}\right)$, and all data were collected on a breath-by-breath basis and reported as 20-s averages. Baseline data were collected while sitting on the bike at rest for $5 \mathrm{~min}$, followed by 3 min of unloaded cycling as a warm-up. This was followed by the symptom-limited maximal exercise phase, which consisted of increasing levels of tension on the bike at a rate of $5 \mathrm{or} 10 \mathrm{~W} \cdot \mathrm{min}^{-1}$ until exhaustion. All patients were in normal sinus rhythm during the CPET.

Parameters were measured at metabolic isotimes expressed as per cent maximal $\left(V^{\prime} \mathrm{CO}_{2}\right.$, max $)$ obtained during the baseline CPET. For instance, patient 1 had a $V^{\prime} \mathrm{CO}_{2}$, max on the baseline CPET of $0.941 \mathrm{~mL} \cdot \mathrm{min}^{-1}$. In this example, parameters were measured at $100 \% V^{\prime} \mathrm{CO}_{2}, \max \left(0.941 \mathrm{~mL} \cdot \mathrm{min}^{-1}\right), 75 \% V^{\prime} \mathrm{CO}_{2}$, max $\left(0.706 \mathrm{~mL} \cdot \mathrm{min}^{-1}\right)$ and $50 \% V^{\prime} \mathrm{CO}_{2}$, $\max \left(0.471 \mathrm{~mL} \cdot \mathrm{min}^{-1}\right)$ during the baseline and 6-month CPETs to match metabolic workloads.

\section{Variables calculated}

Pulse pressure

Blood pressure (BP) was measured manually using a sphygmomanometer and stethoscope at rest and every 2 min during the CPET.

$$
\text { Pulse pressure }=\text { systolic BP-diastolic BP }
$$

\section{Oxygen pulse}

Oxygen pulse, a non-invasive marker of stroke volume [12-14], was calculated from $V^{\prime} \mathrm{O}_{2}$ and cardiac frequency $(f \mathrm{C})$ collected breath-by-breath during the CPET as previously described [22].

$$
\text { Oxygen pulse }\left(\mathrm{mL} \cdot \text { beat }^{-1}\right)=V^{\prime} \mathrm{O}_{2} / f \mathrm{C}
$$

\section{Measurement of dynamic lung volumes}

In order to measure end-expiratory lung volume (EELV) during exercise, the inspiratory capacity (IC) was measured by instructing the patient to inhale deeply from functional residual capacity (FRC) to TLC as previously reported. Because TLC changes at most minimally during exercise [23], EELV can be calculated by subtracting IC from TLC.

$$
\mathrm{EELV}=\mathrm{TLC}-\mathrm{IC}
$$

Patients were instructed in the technique of performing the IC manoeuvre and three IC measurements were taken during the baseline phase of CPET. The baseline IC reported is the mean of these three measurements. The IC was measured every 2 min throughout exercise. The EELV/TLC ratio at peak exercise was the marker of $\mathrm{DH}$.

\section{Statistical analysis}

Data are reported as median (interquartile range). Baseline characteristics were compared using the Mann-Whitney U-test. Changes in exercise parameters at metabolic isotimes $\left(V^{\prime} \mathrm{CO}_{2}\right.$,max, see "Cardiopulmonary exercise testing") were compared within groups using the Wilcoxon signed rank test. Comparisons between groups in changes of pulmonary function and oxygen pulse/PP were performed using the Mann-Whitney U-test. Correlations between changes in oxygen pulse and PP and changes in lung volumes were performed using Spearman rank order correlations. A p-value of $<0.05$ was considered statistically significant.

\section{RESULTS}

\section{Study participants}

Baseline characteristics are displayed in table 1. Compared with the non-LVRS group, LVRS patients were older, more likely to be male and had a higher FEV1. Lung volumes (RV, TLC and EELV/TLC), were similar between groups. The use of respiratory medicines (bronchodilators, inhaled corticosteroids and prednisone) did not differ between groups. There were no changes in medications over the 6 month period in either group.

\section{Changes in pulmonary function and exercise parameters at 6 months}

Changes in pulmonary function, $\mathrm{DH}$, and work performed on CPET are shown in table 2. From baseline to 6 months, the LVRS group had greater increases in FEV1 and FEV1/forced vital capacity. Compared with the non-LVRS group, RV and 
TABLE 1 Baseline patient characteristics

\begin{tabular}{lccc} 
& LVRS & Non-LVRS & p-value \\
\hline Subjects n & 16 & 6 & \\
Age yrs & $67.0(63.8-72.2)$ & $58.5(55.3-60.8)$ & 0.02 \\
Males \% & 63 & 17 & 0.15 \\
FEV 1 L & $0.79(0.65-0.95)$ & $0.53(0.48-0.68)$ & 0.03 \\
FEV 1 \% pred & $24.5(22.0-36.3)$ & $20.5(17.5-22.8)$ & 0.03 \\
TLC \% pred & $125(108-133)$ & $134(128-144)$ & 0.08 \\
RV \% pred & $191(161-250)$ & $235(219-265)$ & 0.22 \\
FRC/TLC \% & $75(73-79)$ & $81(73-82)$ & 0.08 \\
EELV/TLC at peak & $0.86(0.80-0.90)$ & $0.87(0.84-0.89)$ & 0.82 \\
$\quad$ & & & \\
exercise & $40.0(34-59)$ & $30.0(24-45)$ & 0.13 \\
Peak power W & $55(55-65)$ & $62.5(45-65)$ & 0.42 \\
LVEF \% & $27.0(24.9-29.3)$ & $24.5(20.3-27.5)$ & 0.20 \\
BMI kg $\cdot$ m $^{-2}$ & $63.0(42.3-85.0)$ & $60.0(47.0-63.8)$ & 0.71 \\
Smoking history & & & \\
$\quad$ pack-years & & &
\end{tabular}

Data are expressed as median (interquartile range), unless otherwise stated LVRS: lung volume reduction surgery; FEV1: forced expiratory volume in $1 \mathrm{~s} ; \%$ pred: \% predicted; TLC: total lung capacity; RV: residual volume; FRC: functional residual capacity; EELV: end-expiratory lung volume; LVEF: left ventricular ejection fraction; BMI: body mass index.

TLC tended to be lower following LVRS after 6 months, but this did not reach statistical significance. $\mathrm{DH}$, as measured by the EELV/TLC ratio, had a greater reduction at 6 months in the LVRS compared with the non-LVRS group. Patients in the LVRS group performed more work during the 6-month CPET, but not to the level of statistical significance.

\section{Changes in non-invasive measures of stroke volume from baseline to 6 months}

When assessed at metabolic isotimes (per cent $V^{\prime} \mathrm{CO}_{2}, \mathrm{max}$ ), there was a statistically significant increase in oxygen pulse in the

\begin{tabular}{|c|c|c|c|}
\hline \multirow[t]{2}{*}{ TABLE 2} & \multicolumn{3}{|c|}{$\begin{array}{l}\text { Changes from baseline to } 6 \text { months later in } \\
\text { pulmonary function, dynamic hyperinflation } \\
\text { during exercise and work performed on } \\
\text { cardiopulmonary exercise test }\end{array}$} \\
\hline & LVRS & Non-LVRS & p-value \\
\hline Subjects & 16 & 6 & \\
\hline$\Delta \mathrm{FEV} \mathbf{1}_{1} \mathrm{~L}$ & $0.48(0.16-0.68)$ & $-0.05(-0.07-0.02)$ & $<0.001$ \\
\hline$\Delta$ FEV $1 /$ FVC $\%$ & $5.0(2.3-6.0)$ & $-2.5(-3.3--0.8)$ & $<0.001$ \\
\hline$\Delta$ TLC $\%$ pred & $-7.5(-18.0-3.3)$ & $-0.5(-7.0-29.5)$ & 0.12 \\
\hline$\Delta \mathrm{RV} \%$ pred & $-35.0(-72.8--4.3)$ & $-6.5(-22.8-24.5)$ & 0.1 \\
\hline$\triangle \mathrm{FRC} / \mathrm{TLC} \%$ & $-10.0(-15.9--4.8)$ & $4.0(-4.4-8.6)$ & 0.01 \\
\hline$\Delta \mathrm{EELV/TLC}$ & $-0.09(-0.12--0.02)$ & $0.02(-0.01-0.04)$ & 0.007 \\
\hline$\Delta$ power W & $10.0(3.3-20.5)$ & $1.5(-1.0-6.3)$ & 0.054 \\
\hline
\end{tabular}

Data are expressed as $\mathrm{n}$ or median (interquartile range), unless otherwise stated. LVRS: lung volume reduction surgery; $\Delta$ : change; FEV1: forced expiratory volume in $1 \mathrm{~s}$; FVC: forced vital capacity; TLC: total lung capacity; $\%$ pred: \% predicted; RV: residual volume; FRC: functional residual capacity; EELV: end-expiratory lung volume.
LVRS group from baseline to 6 months at all measured exercise time-points (table 3 ). There was no increase in oxygen pulse in the non-LVRS group when measured at the same time-points. For PP, the LVRS group experienced a significant increase during submaximal exercise $\left(50 \%\right.$ and $75 \% V^{\prime} \mathrm{CO}_{2}$,max) at 6 months; there was no such change in the non-LVRS group (table 4).

Figure 1 displays the change in oxygen pulse and PP at metabolic isotimes from baseline to 6 months in the LVRS and non-LVRS groups. Comparing the LVRS with the non-LVRS group (fig. 1a), there were greater increases in oxygen pulse at $50 \% V^{\prime} \mathrm{CO}_{2}$, $\max (\mathrm{p}=0.04)$ and $75 \% V^{\prime} \mathrm{CO}_{2}$, max $(\mathrm{p}=0.04)$. There were no statistically significant differences in the change in PP at 6 months between groups (fig. 1b).

\section{Correlations between changes in non-invasive markers of stroke volume and changes in lung volumes}

Throughout both groups at baseline and 6 months, there was a significant negative correlation between EELV/TLC and oxygen pulse (fig. 2). Reductions in hyperinflation correlated with an increase in oxygen pulse. A decrease in static hyperinflation (FRC/TLC) significantly correlated with an increase in resting oxygen pulse at 6 months $(\mathrm{r}=-0.449, \mathrm{p}=0.04 ; \mathrm{n}=22)$ (fig. 3$)$. A decrease in $\mathrm{DH}$ (EELV/TLC) correlated with an increase in $\mathrm{O}_{2}$ pulse at $75 \% V^{\prime} \mathrm{CO}_{2}$, max $(\mathrm{r}=-0.487, \mathrm{p}=0.02 ; \mathrm{n}=22)$ and $100 \%$ $V^{\prime} \mathrm{CO}_{2}$, $\max (\mathrm{r}=-0.548, \mathrm{p}=0.008 ; \mathrm{n}=22)$ (fig. 4). When correlations were performed using only the LVRS group, the relationship between change in oxygen pulse and change in EELV/TLC at $50 \% V^{\prime} \mathrm{CO}_{2}$, max and $75 \% V^{\prime} \mathrm{CO}_{2}$, max was no longer significant; a statistically significant correlation persisted when EELV/TLC was measured at $100 \% V^{\prime} \mathrm{CO}_{2}$, max.

\section{DISCUSSION}

The major finding of this study is that LVRS improved noninvasive markers of cardiac stroke volume during exercise. Oxygen pulse and PP were significantly increased 6 months after LVRS, whereas these markers were not changed in emphysema patients with comparable levels of hyperinflation who did not undergo LVRS. Increased lung volumes correlated

\begin{tabular}{|c|c|c|c|c|}
\hline \multirow[t]{2}{*}{ TABLE 3} & \multicolumn{4}{|c|}{$\begin{array}{l}\text { Oxygen pulse measured at metabolic isotimes at } \\
\text { baseline and } 6 \text { months }\end{array}$} \\
\hline & LVRS $\mathrm{O}_{2}$ pulse & $p$-value & Non-LVRS $\mathrm{O}_{2}$ pulse & p-value \\
\hline \multicolumn{5}{|l|}{$50 \% V^{\prime} \mathrm{CO}_{2}$} \\
\hline Baseline & $5.7(4.9-6.8)$ & 0.006 & $4.1(3.7-5.7)$ & 0.84 \\
\hline 6 months & $6.3(5.5-8.0)$ & & $4.3(4.0-4.8)$ & \\
\hline \multicolumn{5}{|l|}{$75 \% V^{\prime} \mathrm{CO}_{2}$} \\
\hline Baseline & $6.6(5.2-8.0)$ & 0.01 & $4.7(4.0-6.0)$ & 0.84 \\
\hline 6 months & $7.0(6.3-8.9)$ & & $4.9(3.9-5.6)$ & \\
\hline \multicolumn{5}{|l|}{$100 \% V^{\prime} \mathrm{CO}_{2}$} \\
\hline Baseline & $7.2(5.7-9.2)$ & 0.02 & $5.5(4.3-6.8)$ & 0.81 \\
\hline 6 months & $8.3(6.6-10.2)$ & & $5.5(4.4-7.1)$ & \\
\hline
\end{tabular}

Data are presented as median (interquartile range), unless otherwise stated Comparisons are made within-group (e.g. $\mathrm{O}_{2}$ pulse at 50\% maximal carbon dioxide production $\left(\mathrm{V}^{\prime} \mathrm{CO}_{2}\right.$, max $)$ for lung volume reduction surgery (LVRS) at baseline versus 6 months). 


\begin{tabular}{|c|c|c|c|c|}
\hline \multirow[t]{2}{*}{ TABLE 4} & \multicolumn{4}{|c|}{$\begin{array}{l}\text { Pulse pressure (PP) measured at metabolic } \\
\text { isotimes at baseline and } 6 \text { months }\end{array}$} \\
\hline & LVRS PP & $p$-value & Non-LVRS PP & p-value \\
\hline \multicolumn{5}{|l|}{$50 \% V^{\prime} \mathrm{CO}_{2}$} \\
\hline Baseline & $46.0(42.0-65.8)$ & 0.03 & $74.0(59.5-80.5)$ & 0.69 \\
\hline 6 months & $62.0(49.0-79.0)$ & & $57.0(49.5-87.0)$ & \\
\hline \multicolumn{5}{|l|}{$75 \% \vee^{\prime} \mathrm{CO}_{2}$} \\
\hline Baseline & $68.0(53.0-77.5)$ & 0.02 & $85.0(65.0-105.5)$ & 0.84 \\
\hline 6 months & $76.0(64.0-89.0)$ & & $78.0(68.5-92.5)$ & \\
\hline \multicolumn{5}{|l|}{$100 \% V^{\prime} \mathrm{CO}_{2}$} \\
\hline Baseline & $81.0(59.5-106.0)$ & 0.20 & $89.0(80.5-115.5)$ & 1.00 \\
\hline 6 months & $87.0(71.0-115.0)$ & & $99.5(83.5-117.5)$ & \\
\hline
\end{tabular}

Data are presented as median (interquartile range), unless otherwise stated. Comparisons are made within group (e.g. PP at 50\% maximal carbon dioxide production $\left(V^{\prime} \mathrm{CO}_{2}\right.$,max) for lung volume reduction surgery (LVRS) at baseline versus 6 months).

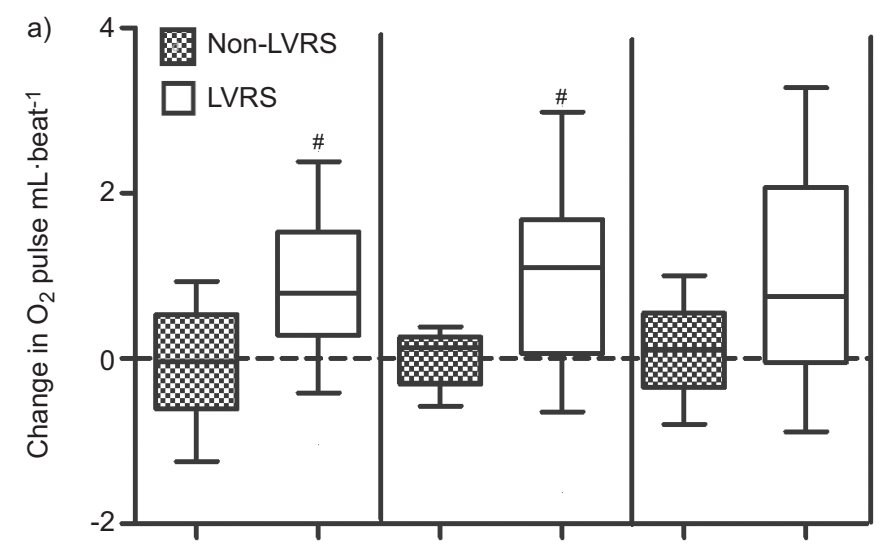

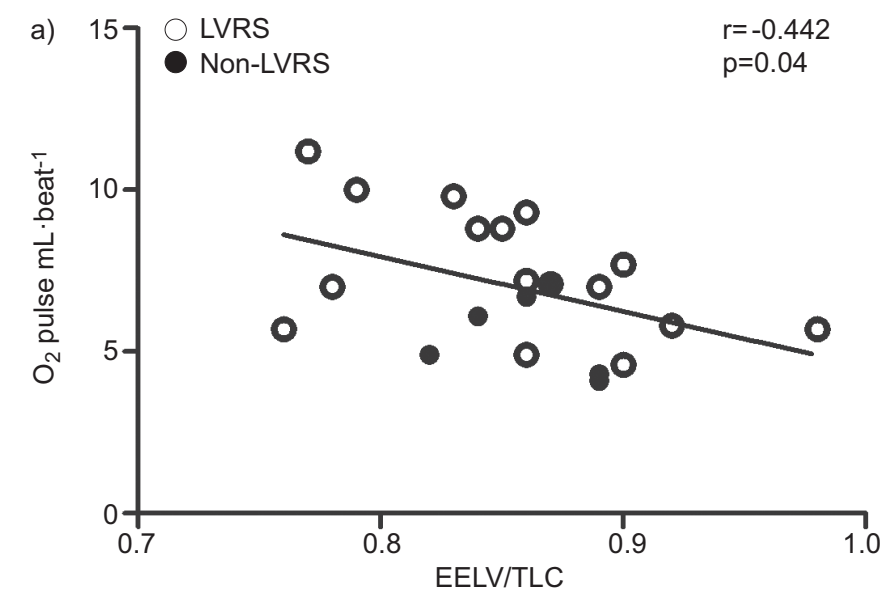

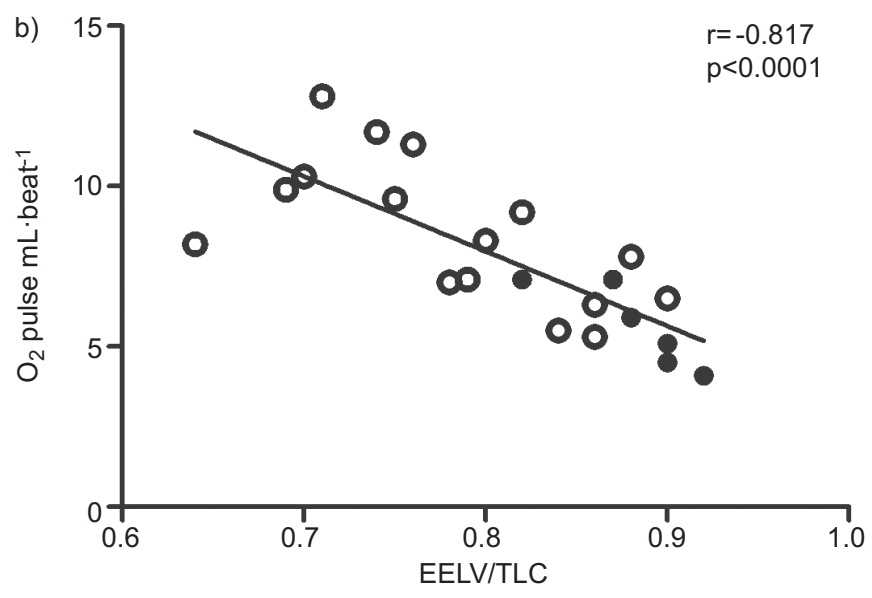

FIGURE 2. Correlation between dynamic hyperinflation (end-expiratory lung volume (EELV)/total lung capacity (TLC)) and oxygen pulse at 100\% maximal carbon dioxide production $\left(\mathrm{V}^{\prime} \mathrm{CO}_{2}\right.$, $\left.\max \right)$ for both groups at a) baseline and b) 6 months. Significant correlations also existed when oxygen pulse was measured at $50 \%$ and $75 \% V^{\prime} \mathrm{CO}_{2}$,max (data not shown). LVRS: lung volume reduction surgery.

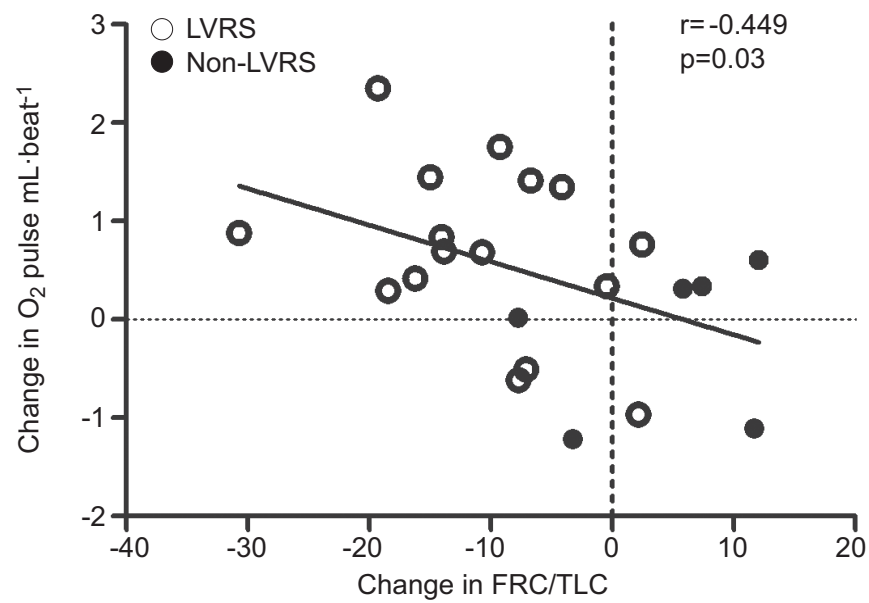

FIGURE 3. Improvements in static hyperinflation (functional residual capacity (FRC)/total lung capacity (TLC)) correlated with increases in resting oxygen pulse at 6 months $(n=22)$. LVRS: lung volume reduction surgery. 

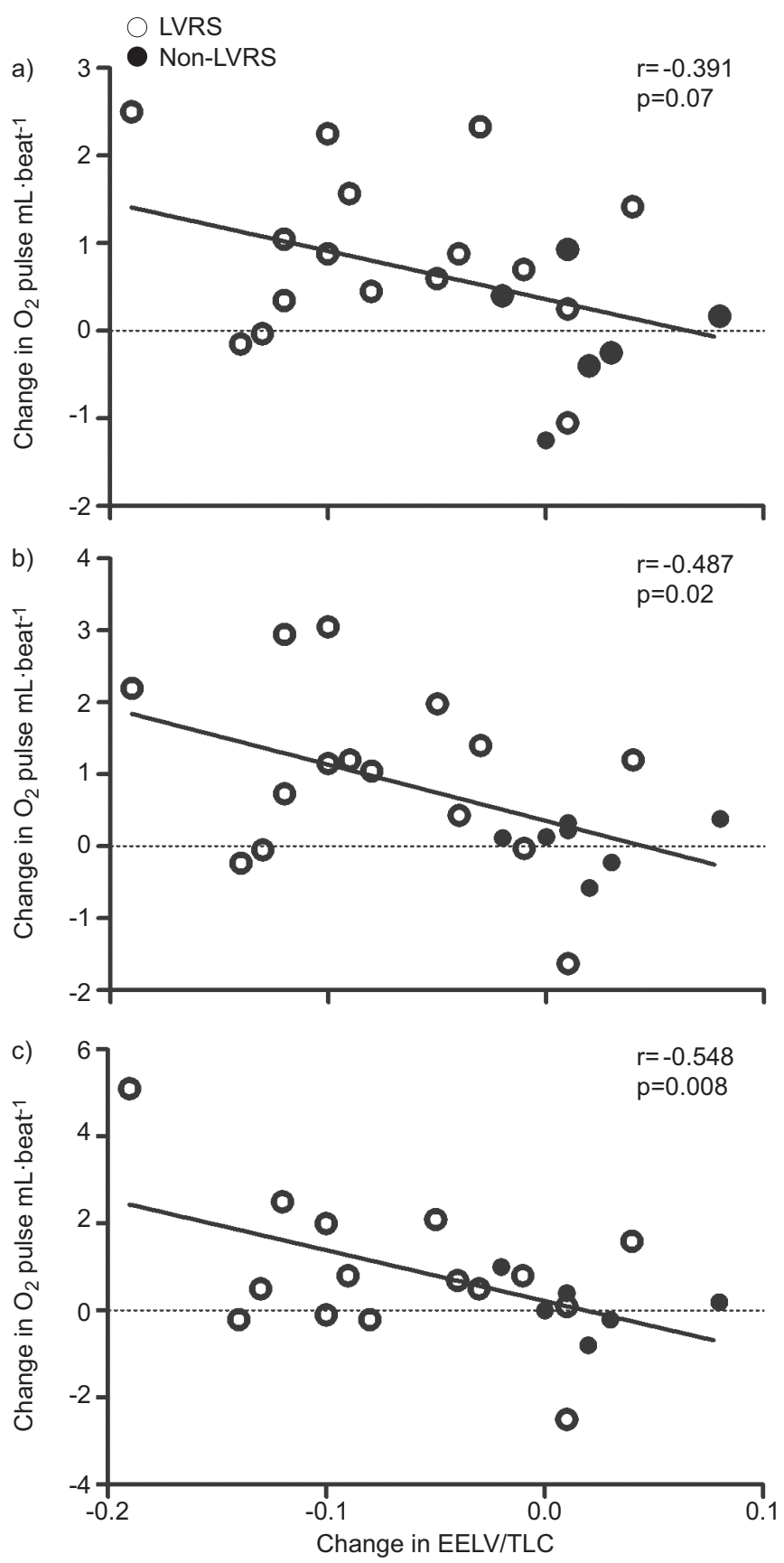

FIGURE 4. Correlation of change (from baseline to 6 months; $n=22$ ) in endexpiratory lung volume (EELV)/total lung capacity (TLC) with change in oxygen pulse at a) $50 \%$ maximal carbon dioxide production $\left(V^{\prime} \mathrm{CO}_{2}\right.$, max $)$, b) $75 \% \mathrm{~V}^{\prime} \mathrm{CO}_{2}$, max c) $100 \% V^{\prime} \mathrm{CO}_{2}$,max. LVRS: lung volume reduction surgery.

with lower oxygen pulse, and we are the first to show that reductions in static hyperinflation and $\mathrm{DH}$ are associated with an improvement in oxygen pulse during exercise.

It has been recognised for decades that hyperinflation in COPD may lead to decreased venous return [6]. JoRGENSEN et al. [5] used magnetic resonance imaging to show that multiple cardiac parameters were impaired in severe COPD. Decreased intrathoracic blood volume correlated with left ventricular end-diastolic index and stroke volume index; however, no measures of lung volumes were reported. While most studies showing similar findings have been conducted in severe COPD, recent studies have shown that impaired left ventricle (LV) filling is related to per cent emphysema on computed tomography scan even in cases of mild airflow obstruction [24]. WATZ et al. [25] extended these findings by demonstrating that hyperinflation correlated with decreased LV end-diastolic diameter across all Global Initiative for Chronic Obstructive Lung Disease stages. Importantly, impaired LV diastolic filling was independently associated with reduced 6-min walk distance [25]. Thus, reducing hyperinflation and improving stroke volume, as shown in our study, may lead to improved functional status.

The stroke volume response to exercise is diminished in COPD due to reduced preload, as evidenced by a lack of decrease in right ventricular end-systolic volume [3]. Impaired cardiac filling and increased pulmonary capillary wedge pressure (Ppcw) during exercise in COPD appears to relate to gas trapping [4]. However, evidence that decreased filling and stroke volume during exercise is related to $\mathrm{DH}$ is sparse.

If cardiac performance is impaired by hyperinflation in COPD, then it would be expected that LVRS would improve filling and stroke volume by reducing hyperinflation. By increasing preload, LVRS led to immediate post-operative increases in cardiac index and stroke volume index [5]. In addition to its immediate effects, an increased RV stroke volume induced by LVRS persists until at least 3 months after surgery [8]. LVRS has been shown to lower $P$ pcw without a change in pulmonary artery pressure [26-28]. Therefore the lowered wedge pressure may be due to reduced intrathoracic pressures. In one study, LVRS improved the stroke volume response to exercise; this improvement correlated to a reduction in static hyperinflation [11].

Many of the aforementioned studies have relied on invasive measures of cardiac performance. Oxygen pulse is a noninvasive measure that correlates well to stroke volume during exercise $[12,14]$. Prior studies investigating the effect of LVRS on oxygen pulse have yielded inconsistent results. Oxygen pulse has repeatedly been shown to increase after LVRS at peak exercise [10, 29, 30]. However, it is possible that the oxygen pulse is proportionally increased due to higher workloads performed after LVRS. The present study avoids this confounding factor by matching metabolic isotimes. Oygen pulse was significantly higher after LVRS when measured at $100 \%$ $V^{\prime} \mathrm{CO}_{2}$, $\max$, which is independent of external workload. Only one prior study [30] demonstrated an improvement in oxygen pulse during submaximal exercise after LVRS. In our study there were increases in oxygen pulse at $50 \% \mathrm{~V}^{\prime} \mathrm{CO}_{2}$, max and $75 \%$ $V^{\prime} \mathrm{CO}_{2}$,max, which is clinically important since most activities of daily living are performed at submaximal levels, not peak exercise [31]. The differing results compared to prior studies may be due to the fact that, after an intervention such as LVRS, metabolic isotimes may theoretically be a better comparator as opposed to isowatt exercise.

The present study extends prior work by VASSAUX et al. [32], who investigated 87 COPD patients and 46 matched healthy controls. They found significant correlation between IC/TLC and oxygen pulse at rest, as well as during exercise. Those with COPD and IC /TLC $<25 \%$ had a lower peak oxygen pulse than those with a ratio $>25 \%$, and in multivariate analysis, the IC/TLC 
was an independent predictor of oxygen pulse. Therefore, the reduced oxygen pulse at rest and during exercise in COPD was related to static hyperinflation and $\mathrm{DH}$. We have further strengthened this conclusion by demonstrating for the first time that LVRS, by reducing hyperinflation, leads to an improvement in oxygen pulse. A recent study [33] demonstrated that, in the NETT cohort, a reduction in static hyperinflation after LVRS was associated with an increased isowork oxygen pulse. Due to the fact that we were able to measure IC during exercise, we could directly associate reductions in $\mathrm{DH}$ to improvements in oxygen pulse, which is a more physiologically relevant relationship than static hyperinflation.

This is the first study to demonstrate an improvement in PP, another non-invasive measure of stroke volume [15, 16], during exercise after LVRS. However, improvements in PP did not correlate with reductions in lung volumes after LVRS. This may be due to the fact that PP not only depends on stroke volume, but also on vascular properties such as endothelial function [34] and aortic compliance [35]. The effects of LVRS on endothelial function and aortic compliance are currently unknown, and thus future studies are needed to address this issue.

The present study has limitations. The overall sample size is small and this is a retrospective analysis, although statistically significant differences were found that are consistent physiologically and supported by prior literature. Also, we used a non-invasive measure of stroke volume (oxygen pulse), which requires the assumption that the arteriovenous oxygen content difference $\left(\mathrm{Ca}_{2} \mathrm{O}_{2}-\mathrm{Cv}_{\mathrm{v}} \mathrm{O}_{2}\right)$ remains constant during exercise. Prior studies of $\mathrm{Ca}_{1} \mathrm{O}_{2}-\mathrm{Cv}_{2}, \mathrm{O}_{2}$ during exercise in COPD patients have yielded conflicting results, with some suggesting that extraction is stable during exercise [36, 37], whereas others [38] found that oxygen extraction during exercise in COPD is lower than that of normal subjects. Compared with the LVRS group, the non-LVRS group was different in demographics and level of airflow obstruction, but there were no significant differences in baseline static or dynamic lung volumes, which were the physiological measurements of interest in this study. Additionally, we investigated changes (rather than baseline differences) in exercise parameters, which should be less influenced by differences between groups. All patients exercised on $30 \% \mathrm{FI}, \mathrm{O}_{2}$, which could have influenced $V^{\prime} \mathrm{O}_{2}$ and subsequently oxygen pulse. However, the level of supplemental oxygen was standardised and changes in oxygen pulse were analysed; therefore, supplemental oxygen should not have affected our conclusions.

\section{Conclusions}

In summary, LVRS improved non-invasive markers of stroke volume (oxygen pulse and PP) during exercise and the increase in oxygen pulse seen after LVRS correlated with reductions in static and DH. Therefore, the impaired stroke volume response to exercise that is known to occur in COPD appears to correlate with DH. More importantly, by reducing lung volumes, LVRS had a favourable effect on stroke volume measured by oxygen pulse. Whether decreasing hyperinflation and increasing cardiac filling and stroke volume leads to an improved functional status should be evaluated in future studies.

\section{STATEMENT OF INTEREST}

A statement of interest for N. Marchetti can be found at www.erj. ersjournals.com/site/misc/statements.xhtml

\section{REFERENCES}

1 O'Donnell DE. Hyperinflation, dyspnoea, and exercise intolerance in chronic obstructive pulmonary disease. Proc Am Thorac Soc 2006; 3: 180-184.

2 Nici L. Mechanisms and measures of exercise intolerance in chronic obstructive pulmonary disease. Clin Chest Med 2000; 21: 693-704.

3 Holverda S, Rietema H, Westerhof N, et al. Stroke volume increase in exercise in chronic obstructive pulmonary disease is limited by increased pulmonary artery pressure. Heart 2009; 95: 137-141.

4 Butler J, Schrijen F, Henriquez A, et al. Cause of the raised wedge pressure on exercise in chronic obstructive pulmonary disease. Am Rev Respir Dis 1988; 138: 350-354.

5 Jörgensen K, Müller MF, Nel J, et al. Reduced intrathoracic blood volume and left and right ventricular dimensions in patients with severe emphysema: an MRI study. Chest 2007; 131: 1050-1057.

6 Nakhjavan FK, Palmer WH, McGregor M. Influence of respiration on venous return in pulmonary emphysema. Circulation 1966; 33: 8-16.

7 Fishman A, Martinez F, Naunheim $\mathrm{K}$, et al. A randomized trial comparing lung-volume-reduction surgery with medical therapy for severe emphysema. N Engl J Med 2003; 348: 2059-2073.

8 Sciurba FC, Rogers RM, Keenan RJ, et al. Improvement in pulmonary function and elastic recoil after lung-reduction surgery for diffuse emphysema. N Engl J Med 1996; 334: 1095-1099.

9 Criner GJ, Belt P, Sternberg AL, et al. Effects of lung volume reduction surgery on gas exchange and breathing pattern during maximal exercise. Chest 2009; 135: 1268-1279.

10 Ferguson GT, Fernandez E, Zamora MR, et al. Improved exercise performance following lung volume reduction surgery for emphysema. Am J Respir Crit Care Med 1998; 157: 1195-1203.

11 Mineo TC, Pompeo E, Rogliani $\mathrm{P}$, et al. Effect of lung volume reduction surgery for severe emphysema on right ventricular function. Am J Respir Crit Care Med 2002; 165: 489-494.

12 Bhambhani Y, Norris S, Bell G. Prediction of stroke volume from oxygen pulse measurements in untrained and trained men. Can J Appl Physiol 1994; 19: 49-59.

13 Crisafulli A, Piras F, Chiappori P, et al. Estimating stroke volume from oxygen pulse during exercise. Physiol Meas 2007; 28: 1201-1212.

14 Whipp BJ, Higgenbotham MB, Cobb FC. Estimating exercise stroke volume from asymptotic oxygen pulse in humans. J Appl Physiol 1996; 81: 2674-2679.

15 Koeppen BM, Stanton BA. Berne and Levy Physiology. 6th Edn. St Louis: Mosby Publishing, 2009; pp. 338-340.

16 Levick JR. An Introduction to Cardiovascular Physiology. 5th Edn. New York: Oxford University Press, 2010; pp. 112-113.

17 American Thoracic Society. Standardization of spirometry, 1994 update. Am J Respir Crit Care Med 1995; 152: 1107-1136.

18 Hankinson JL, Odencrantz JR, Fedan KB. Spirometric reference values from a sample of the general U.S. population. Am J Respir Crit Care Med 1999; 159: 179-187.

19 Stocks J, Quanjer PH. Reference values for residual volume, functional residual capacity and total lung capacity. ATS workshop on lung volume measurements. Official statement of the European Respiratory Society. Eur Respir J 1995; 8: 492-506.

20 American Thoracic Society. Single-breath carbon monoxide diffusing capacity (transfer factor). Recommendations for a standard technique: 1995 update. Am J Respir Crit Care Med 1995; 152: 2185-2198.

21 American Thoracic Society, American College of Chest Physicians. ATS/ACCP statement on cardiopulmonary exercise testing. Am J Respir Crit Care Med 2003; 167: 211-277.

22 Wassmerman K, Hansen JE, Sue DY, et al. Principles of Exercise Testing and Interpretation: Including Pathophysiology and Clinical Applications. 4th Edn. Philadelphia, Lippincott, Williams, and Wilkins, 2004; pp. 91-92. 
23 Stubbing DG, Pengelly LD, Morse JLC, et al. Pulmonary mechanics during exercise in subjects with chronic airflow obstruction. J Appl Physiol 1980; 49: 511-515.

24 Barr RG, Bluemke DA, Ahmed FS, et al. Percent emphysema, airflow obstruction, and impaired left ventricular filling. $N$ Engl J Med 2010; 362: 217-227.

25 Watz H, Waschki B, Meyer T, et al. Decreasing cardiac chamber sizes and associated heart dysfunction in COPD: role of hyperinflation. Chest 2010; 138: 32-38.

26 Kubo K, Boizumi T, Fujimoto K, et al. Effects of lung volume reduction surgery on exercise pulmonary hemodynamics in severe emphysema. Chest 1998; 114: 1575-1582.

27 Haniuda M, Kubo K, Fujimoto K, et al. Different effects of lung volume reduction surgery and lobectomy on pulmonary circulation. Ann Surg 2000; 231: 119-125.

28 Criner GJ, Scharf SM, Falk JA, et al. Effect of lung volume reduction surgery on resting pulmonary hemodynamics in severe emphysema. Am I Respir Crit Care Med 2007; 176: 253-260.

29 Benditt JO, Lewis S, Wood DE, et al. Lung volume reduction surgery improves maximal $\mathrm{O}_{2}$ consumption, maximal minute ventilation, $\mathrm{O}_{2}$ pulse and dead space-to-tidal volume ratio during leg cycle ergometry. Am J Respir Crit Care Med 1997; 156: 561-566.

30 Cordova F, O'Brien G, Furukawa S, et al. Stability of improvements in exercise performance and quality of life following bilateral lung volume reduction surgery in severe COPD. Chest 1997; 112: 907-915.
31 McArdle WD, Katch FI, Katch VL. Human energy expenditure during rest and physical activity. In: McArdle WD, Katch FI, Katch VL, eds. Exercise Physiology: Energy, Nutrition, and Human Performance. 3rd Edn. Philadelphia: Lea and Febiger, 1991; pp. 158-173.

32 Vassaux C, Torre-Bouscoulet, Zeinedline S, et al. Effects of hyperinflation on the oxygen pulse as a marker of cardiac performance in COPD. Eur Respir J 2008; 32: 1275-1282.

33 Come CE, Divo MJ, Estepar RSJ, et al. Lung deflation and oxygen pulse in COPD: results from the NETT randomized trial. Respir Med 2012; 106: 109-119.

34 McEnjery C, Wallace S, Mackenzie IS, et al. Endothelial function is associated with pulse pressure, pulse wave velocity, and augmentation index in healthy humans. Hypertension 2006; 48: 602-608.

35 Cavalcante JL, Lima JA, Redheuil A, et al. Aortic stiffness: current understanding and future directions. I Am Coll Cardiol 2011; 57: 1511-1522.

36 Light RW, Mintz HM, Linden GS, et al. Hemodynamics of patients with severe chronic obstructive pulmonary disease during progressive upright exercise. Am Rev Respir Dis 1984; 130: 391-395.

37 Sala E, Roca J, Marrades RM, et al. Effects of endurance training on skeletal muscle bioenergetics in chronic obstructive pulmonary disease. Am J Respir Crit Care Med 1999; 159: 1726-1734.

38 Oelberg DA, Kacmarek RM, Pappagianopoulos PP, et al. Ventilatory and cardiovascular responses to inspired $\mathrm{He}-\mathrm{O}_{2}$ during exercise in chronic obstructive pulmonary disease. Am J Respir Crit Care Med 1998; 158: 1876-1882. 